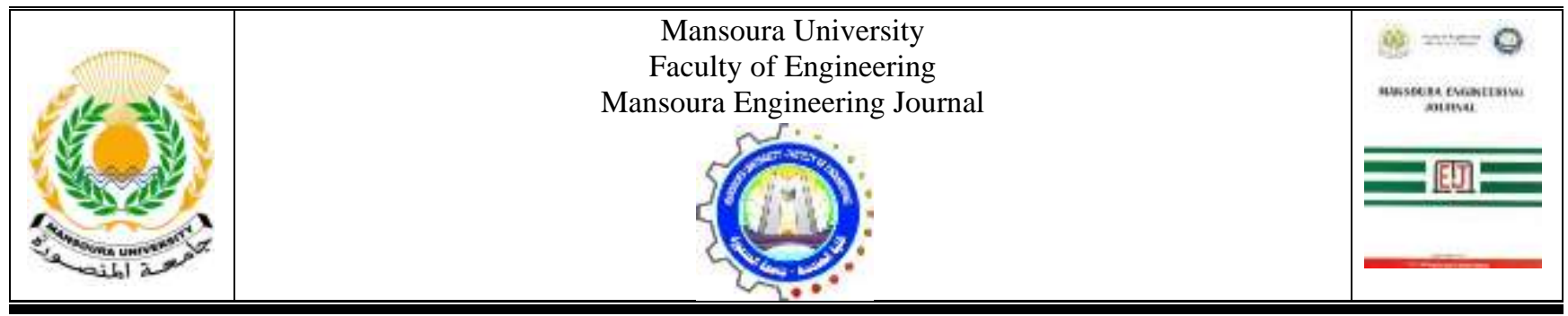

\title{
Comparative Performance of Domestic Refrigerator by Using Constant and Variable Speed Compressors with HC and HFC Refrigerants

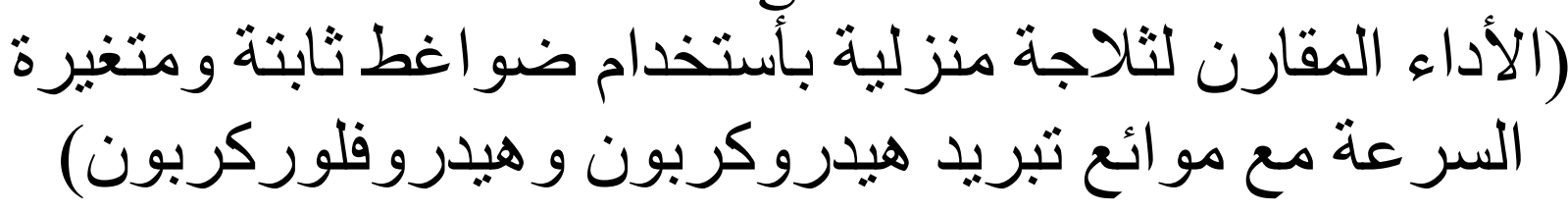

Y. G. Nasr, EL-Sadek H. NourEldeen, K. Harby and A.M. El-Kersh

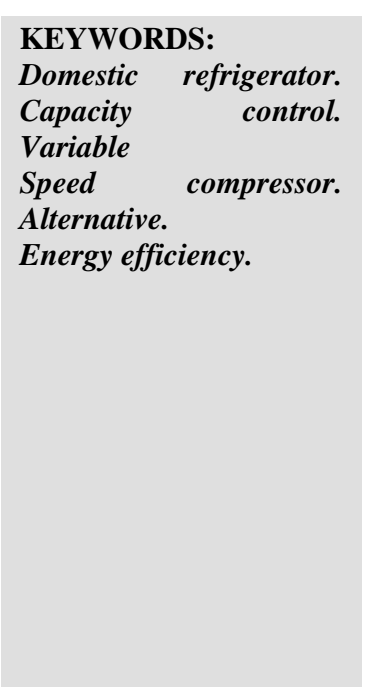

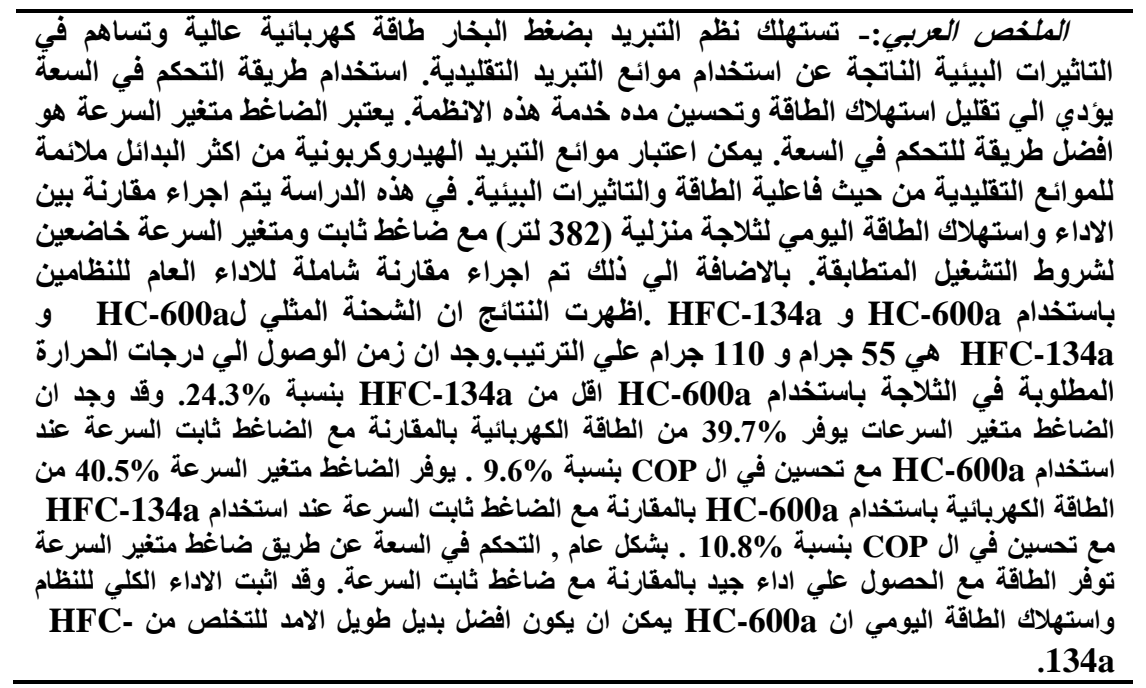

2018

Received: 1 April, 2018 - revised: 24 June, 2018 - accepted: 19 August,

$Y$. G. Nasr is a demonstrator at mechanical power and energy department Minya university

EL-Sadek H. NourEldeen is now a lecturer at the Department of mechanical power and energy, Minia University and he was with Moscow state University, Russia. (e-mail: dr_elsadekhn2000@mu.edu.eg).

K. Harby is now an Associate Professor at the Department of mechanical power and energy, Minia University and he was with polytechnic university of Valencia, Spain.(E-mail: khaled.h@mu.edu.eg).
Abstract - Vapor compression cooling systems consume high electrical energy and contribute to environmental impacts due to the used of traditional harmful working fluids. Use of a capacity control method can reduce energy consumption and improve service life of these systems. Variable speed compressor is considered as the best and most efficient method of capacity control. Hydrocarbons can be considered as the most proper alternatives to traditional refrigerants in terms of energy efficacy and environmental impacts. In the actual work a comparison

A.M. El-Kersh is now an Emeritus professor at the Department of mechanical power and energy, Minia University and he was with paisley college of technology, Scotland UK. (e-mail: elkersh@mu.edu.eg). 
between the performance and daily energy consumption of a household refrigerator ( 382 liters) with constant and a variable speed compressor subject to identical operation conditions are carried out. In addition, the overall performance of the both systems using HC-600a and HFC-134a refrigerants was carried out and compared.

Results showed that the optimum charges for HC600a and HFC-134a were $55 \mathrm{~g}$ and $110 \mathrm{~g}$ respectively. The pull-down time for HC-600a is lower than that of HFC-134a system by $24.3 \%$. The variable speed compressor system with HC-600a saves about $39.7 \%$ energy consumption in comparison to constant speed compressor system with the same refrigerant with COP enhancement by $9.6 \%$. Using variable speed compressor with HC600a can save energy by about $40.5 \%$ and improve the COP by $10.8 \%$ comparing to constant speed compressor system with HFC-134a. In general, variable-speed capacity control compressor offers more energy savings with better performance compared to constant speed compressor. The overall system performance and the daily energy consumption has proved that HC-600a could be the best long-term alternative to phase out of HFC-134a.

\section{INTRODUCTION}

$\mathrm{E}$ nergy saving and environmental impacts are the most important subject nowadays due to the rapid population growth and rise in the standard of living. Refrigeration plays a fundamental role in sustainable development since it has many applications in different number of fields in our daily lives. The majority of refrigeration and air conditioning equipment employs traditional vapor compression cycle because of its high COP. However, the high-grade energy consumption of this system is very high and its working fluid create environmental impacts that have to be solved quickly [1]. In addition, global Energy consumption increases rapidly because of population increasing and the switching from the simple live standard to the modern one. Refrigeration technology is one part of many that responsible of the highly energy consumption due to the need of conservation of food in household refrigerators. These types of refrigerators are considered as the major energy consumption in domestic appliances [2]. Saving energy will minimize the dependence on fossil fuel and therefore helps in minimizing global warming [3].

Reduction of energy consumption of a refrigeration system can be accomplished by enhancing its performance. This can be achieved by minimizing the power consumption of compressor unit by capacity control methods such as variable variable speed compressors for example.

Variable speed compressor control method is the most energy efficient capacity control method for full and partial load conditions as mentioned by Qureshi [4]. In such technique, the capacity is matched to the load by adjusting the speed of the compressor motor in such a way that it tracks the load. The inverter-driven refrigeration system varies cooling capacity by controlling the compressor speed depending on the applied cooling loads.

There are some studies carried out on the performance investigation of constant and variable speed compressor systems can be found in the literature. However, the relevant experimental data are comparatively rare. Qureshi and Tassou [4] carried out a comparison between the different methods of capacity control in refrigeration. Their results showed that a two-speed, stepwise controlled compressor consumes $49 \%$ less energy than a constant speed compressor (CSC) because at half speeds the friction losses was lower. Also, the cyclic losses of the CSC were higher than variable speed compressor (VSC) by $5-7 \%$. They also reported that using a VSC in refrigerator could improve the energy efficiency by a $15 \%$, compared to a conventional system. Chang et al. [5] investigated the performance of using R600a and R134a in a household refrigerator with fixed frequency compressor (FFC) and a variable frequency compressor (VFC). It was concluded that the household refrigerator using HC-600a-FFC consumes energy of $10.6 \%$ lower than HFC-134a-FFC. However, HC600a-VFC provides $0.829 \mathrm{kWh} / 24 \mathrm{~h}$ decrease in energy consumption as compared to HFC-134a-FFC. Also, for HFC$134 \mathrm{a}$, the energy consumed of VFC is $1.62 \mathrm{kWh} /$ day with an efficient potential of $28.16 \%$ based on the household refrigerator with FFC.

In household refrigerators the $\mathrm{HC}$ refrigerants are preferred due to less refrigerant quantity and high performance compared with the halogenated refrigerants.

The most possible two alternative solutions to chlorofluorocarbon (CFC) and hydrochlorofluorocarbon (HCFC) refrigerants are hydrofluorocarbon (HFC) and hydrocarbon refrigerants (HC). Nowadays researches are developed to substitute HFC refrigerant with HC refrigerants because it has a low level of GWP and a low mass charge comparing to HFC refrigerants [6 and 1]. However, the Montreal Protocol, Kyoto Protocol, and Vienna Convention had united in opinion to phase out HCFCs and CFCs. In household refrigerators the $\mathrm{HC}$ refrigerants are preferred due to less refrigerant quantity and high performance compared with the halogenated refrigerants.

A number of researchers had studied the possibility of using hydrocarbons as alternatives to conventional refrigerants in different cooling applications. In 2016 Harby [3] presented a comprehensive overview on hydrocarbons and their mixtures as alternatives to conventional refrigerants in refrigeration, air conditioning and heat pump, and automobile air conditioning systems. The author presented also the current status, possibilities, and replacement strategy of traditional working fluids, and the problems related to the use of hydrocarbons in refrigeration systems. The author concluded that in spite of highly flammable characteristics, hydrocarbons can offer good alternatives to the conventional refrigerants from the standpoint of environment impact, energy efficiency, COP, and refrigerant mass. Roadmap on the future work needs in this field is also presented. Dhavale and Deshmukh [7] investigated the performance of a domestic refrigerator using blend of propane/isobutene (HC-290/HC-600a) as alternative to HFC-134a. They demonstrated that refrigeration potential and $\mathrm{COP}$ increases when evaporator temperature is increase 
and decreases with constant condensing temperature. The energy consumed was larger than HFC-134a and the mass charge reduced for the alternative refrigerant mixtures due to their low liquid densities. Yu and Teng [8] studied experimentally the usage of hydrocarbon mixture in a small HFC-134a refrigerator. Three mixed mass ratios of $\mathrm{HC}$ 290/HC-600a were used. The studied charged ratios for HC refrigerants based on the charged mass of HFC-134a were $30 \%, 40 \%, 50 \%$ and $60 \%$. The optimal charge of $\mathrm{HC}$ refrigerants was $40 \%$ of HFC-134a. Their results showed that energy consumed of HC-290/HC-600a mixture was higher than that of HFC-134a associated with lower compression ratio. The 24-hour electricity consumption for HC-290/HC$600 \mathrm{a}$ mixture was lower than that of HFC-134a due to reduction in on-time ratio. Rasti et al. [2] analyzed experimentally the performance of HC600a and R436A as a replacement to HFC-134a in a domestic refrigerator. Their results showed that for the same HFC compressor, the optimum charges for R436a and HC-600A were $60 \mathrm{~g}$ and $55 \mathrm{~g}$ respectively. Also, the energy consumed by HC-600a and R436A was reduced by $7 \%$ and $14 \%$ respect to HFC-134a.

In addition, Jwo et al. [9] investigated experimentally the performance of HFC-134a and mixture of HC-290/HC-600a with each $50 \%$ component ratio at different charge on 440 liters' capacity refrigerator. Their results revealed that the use of $\mathrm{HC}-290 / \mathrm{HC}-600$ a with $40 \%$ reduction in mass had the best refrigerating effect with a consumed energy saving of $4.4 \%$. Mohanraj et al. [10] carried out an experimental analysis on the behavior of hydrocarbon mixture (HCM) of HC-290/HC$600 \mathrm{~A}$ as an alternative to HFC-134a in 200 liters domestic refrigerator with different mass charges (40, 50, 60 and $70 \mathrm{~g}$ ). Their results proved that HCM required lengthening the capillary tube by $25 \%$ to achieve higher COP and HCM of 60 $\mathrm{g}$ is the best alternative. It consumes $11.1 \%$ lower energy comparison to that of HFC-134a. Pull down time and on timeratio were minimized by $11.6 \%$ and $13.2 \%$, respectively and the COP was improved up to $3.6 \%$.

Lee et al. [11] investigated experimentally the behavior of a small refrigerator by using $\mathrm{HC}-290 / \mathrm{HC}-600 \mathrm{a}$ as an alternative to HFC-134a. Their results showed that the charge of the HC-290/HC-600a was approximately 50\% of HFC134a. The cooling speed at the in-case setting temperature of $15{ }^{\circ} \mathrm{C}$ was improved by $28.8 \%$ over that of HFC-134a. They found that the lengths of capillary tube for evaporator were longer than those in the HFC-134a system by $500 \mathrm{~mm}$. Also, the power consumption of HFC-134a was higher than that of HC-290/HC-600a by $12.3 \%$.

Sattar et al. [12] tested a 300 liters domestic refrigerator to assess the probability of using hydrocarbons and their blends as replacement to HFC-134a. Refrigerant HC-600a and mixture of HC-290, HC-600 and HC-600a are used. Their results showed that $\mathrm{COP}$ of $\mathrm{HC}$ and its blends was similar to the COP of HFC-134a. Less energy consumed by $2 \%$ and $3 \%$ when HC-600 and HC-600a were used compared with that of HFC134a. Fatouh and El Kafafy [13] investigated experimentally the performance of LPG composed of HC-290, HC-600a and HC-600 (60:20:20 by mass fraction) in a 283 liters domestic refrigerator as alternative to HFC-134a. Their results showed that a reduction by $4.3 \%, 5.5 \%$ and $7.6 \%$, respectively in the power consumption, pressure ratio and pull-down time of LPG refrigerator compared with HFC-134a. The COP was improved by $7.6 \%$ with LPG compared to HFC134a.

According to the above literature review, inverter-based variable-speed drive technology is presently well proven in refrigeration and air conditioning applications. The utilization of variable speed compressor can extremely improve the system performance and energy efficiency. The use of hydrocarbons as working fluid is not just perfect for the environment but also it can minimize the energy consumption and offer display drop-in replacements for the existing conventional refrigerants. In addition, there is not much experimental research available on household refrigerators that combine variable and constant speed with hydrocarbons as alternative to conventional refrigerants.

In this regard, it is the objective of the present study is to conduct a comparative investigation on the performance of constant and variable speed compressor system with HFC and hydrocarbon refrigerant in a household refrigerator. The experimental results of the performance characteristics and daily power consumption for each of constant and variable speed compressor as well as with HFC-143a and HC-600a are compared and analyzed.

\section{EXPERIMENTAL SET-UP}

A commercially available HFC-134a double-door domestic refrigerator with 382 liters and variable speed compressor was used to perform the experiments. The system was prepared with another constant speed compressor, ball valve network, and tube connection. In addition, the system was charged and checked to operate with hydrocarbon (HC600a) refrigerant. Figure 1 presents a schematic diagram of the system with measuring device at each point. The system has a fin-and-tube type counter cross flow forced convection type evaporator and the condenser is in the body of the refrigerator. The system set-up is carried out and tested in the refrigeration and air conditioning lab at the Faculty of Engineering, Minia University.

The pressure-enthalpy relation of cycle which is useful to describe the system from the point of view of energy consumption is shown in Fig. 2. 


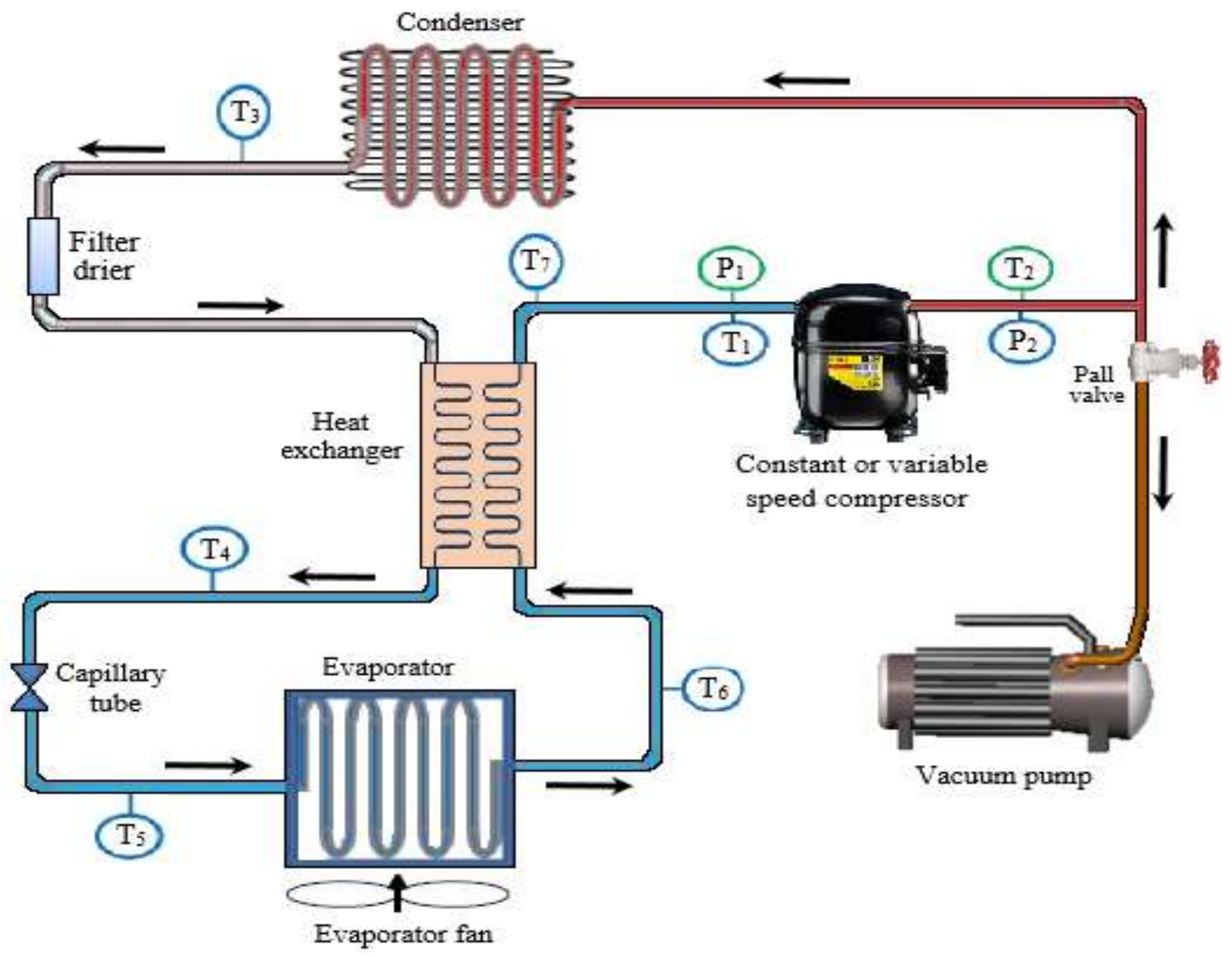

Fig. 1 Schematic diagram of the test unit and measuring devices

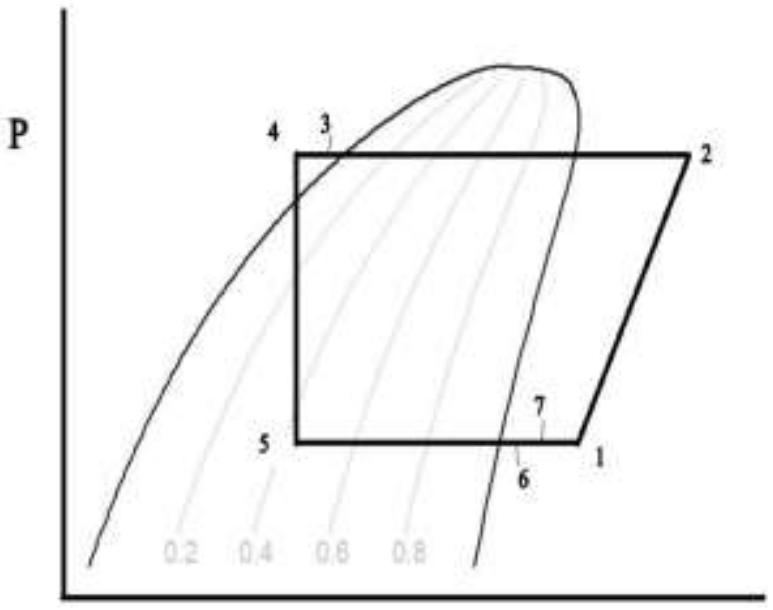

h

Fig. 2 P-h diagram for the system
As shown from Fig. 1, the system consisting mainly of variable and constant speed compressor, air cooled condenser, evaporator, vacuum pump, ball valve network, and capillary tube with lateral type suction line heat exchanger.

To investigate the effect of variable speed compressor on the system performance, the original refrigerator was prepared with another constant-speed compressor. Both compressors having the same rated power (1/3 horsepower) and made from the same compressor manufacturer.

The basic difference between variable and constant speed compressor test is the control of the system capacity at partload conditions. In constant speed compressor systems, the compressor works all the time at the maximum load at the different system capacity. In the variable speed compressor, the capacity of the refrigerator is matched to the load by regulating the speed of the compressor motor in such a way that the capacity of the system tracks the load dictated on it by varying the operating conditions. A variable speed compressor is an interface between the utility input and the compressor 
motor that controls the speed of the motor by changing the magnitude of voltage, current or frequency.

The system has been connected to a vacuum pump as shown in the figure which has been used for evacuation purposes before the beginning of each tests. The optimum HC134a and HC-600a charges were determined experimentally. Through all of tests, ambient temperature around the refrigerator was controlled within $28{ }^{\circ} \mathrm{C}\left( \pm 2^{\circ} \mathrm{C}\right)$ by an environmentally air conditioning room. In addition to the conditioning room, ambient temperature was monitored by the data acquisition system. The starting conditions were the same for all experiments.

In data gathering, pressure, temperature and power were recorded on every trial. The refrigerated cabinet (cabin and freezer compartment) temperatures, operating temperature and pressure of the 4 basic components of the cycle and power of compressors were the parameters included in the comparative analysis as shown in Fig .1. In getting the data for pressure and temperature, a number of calibrated (K-type) thermocouples and pressure transducers are installed. Temperatures, which are important for calculations and analysis of cycle properties, were measured at seven different locations during the experiments. These locations are compressor inlet, compressor outlet (condenser inlet), condenser outlet, hot pipe outlet (capillary tube inlet), evaporator inlet (capillary outlet), and the suction side of heat exchanger outlet. However, thermocouples are calibrated by standard thermometer with $\pm 0.2{ }^{\circ} \mathrm{C}$ accuracy. To install each sensor, the surface of the tube was polished for removing any dust and then the thermocouple probe was laid down on the surface. In addition, glycerin material was used in the point of contact between thermocouple and tube surface in order to minimize the contact resistance. In addition, insulating tape was wrapped around the thermocouple probe to make good contact and prevent any convection effect of ambient air on the temperature readings. To measure the refrigerated cabinet temperatures, six thermocouples are placed inside cabin compartment to measure its average inside temperature and three in the freezer compartment according to the ISO/IEC test standards [14]. For both variable and constant speed compressor test, Water were placed inside the system that will serve as the load for the study.

Pressures are also important for calculations and analyzing the cycle properties, were measured at two different locations during the experiments. These locations include the lowpressure side at the compressor inlet (compressor suction) with a pressure transducer ranged from -1 to 10 bar and the high-pressure sides at the compressor outlet (compressor discharge) with a pressure transducer ranged from 0 to 30 bars. Only double pressure reading at low and high-pressure side is sufficient to calculate and analysis the cycle properties with the temperature readings as mentioned in many previous studies such as [15].

The two pressure transducers with $\pm 0.2 \%$ of full scale reading were installed and brazed on refrigeration line. A watt-meter (UT71E type) ranged from 0 to 3000 Watt with $\pm 0.5 \%$ was used to measure power of each compressor.
However, all the thermocouples, pressure transducers, and watt-meter are connected through a 20-channel data logger (GL820 type), which is connected to a PC. The data logger was programmed to read and save measured data on a computer at 60 second intervals through the entire test.

After finishing each test, data stored by the PC was converted into an excel file. The excel data were copied to a template excel file, which was prepared beforehand and includes important cycle graphs such as refrigerated cabinet temperatures, cycle pressures, and power consumption. After obtaining raw data, the power of each cycle period was found by averaging measured values for one cycle.

\section{Performance ANd Energy CONSUmption Method}

Experimental were carried out under the same cooling load and ambient conditions to assess the effect of constant and variable speed compressors and $\mathrm{HC}-600 \mathrm{a}$ in comparison to HFC-134a (baseline) on the performance of a household refrigerator. The refrigerator was set in an air-conditioned room, under prevailing ambient conditions. To investigate the performance of tested refrigerator, no-load pull-down test and long-term test for energy consumption were carried out.

In the scope of this study, the cabin compartment is empty and the freezer compartment is filled with water which is used as load in the freezer compartment of the test refrigerator during energy consumption test. The refrigerator under test is set to keep the required temperatures of the cabin compartments $7{ }^{\circ} \mathrm{C}$. During the test, the power consumption and the temperatures are measured as shown in previous sections. Measurements of each cabin and freezer compartment are taken once in every 60 seconds and recorded to determine energy consumption of the refrigerator under the test. The EC test continues until the refrigerator under test reaches the steady state operating conditions.

Using the pressure and temperature to get the enthalpy at each point with the help of EES (Engineering Equation Solver)

$h=$ enthalpy (Refrigerant, $T=$ temp.,$P=$ press. $).$. (1) except the enthalpy at the inlet of the evaporator is calculated from

$$
h_{7}-h_{6}=h_{3}-h_{4} \quad \text { and } \quad h_{4}=h_{5}
$$

The overall system COP of the refrigeration cycle which is the ratio of enthalpy difference in the evaporator to enthalpy difference of the compressor.

$$
C O P=\frac{\Delta h_{e}}{\Delta h_{\text {comp }}} .
$$

where $\Delta h_{e}$ and $\Delta h_{\text {comp }}$ represent the enthalpy change of the refrigerant in the evaporator and compressor, respectively.

After calculating on-time and $\mathrm{W}_{\text {Comp }}$, energy consumption of the system cycle can be calculated. The daily energy consumption (DEC) for both constant and variable speed compressors is calculated by integrating the power consumption over the EC test time interval for $24 \mathrm{~h}$ which gives the EC of the refrigerator in $\mathrm{kWh} / 24 \mathrm{~h}$. 
DEC $=\frac{\text { Power Consumption } * \text { on time } * 24 \text { hours }}{\text { Operation Time }}\left(\frac{k W h}{24 h}\right) .$.

Where the total power consumption can be expressed as Power consumption $=\int_{t_{1}}^{t_{2}}$ power consumption $d t$

where $t_{1}$ is the energy consumption test start time and $t_{2}$ is the EC test end time.

The properties of the refrigerants used in the tested refrigerator in the present study are shown in Table 1.

TABLE 1:

PROPERTIES OF REFRIGERANTS USED IN THE TESTED REFRIGERATOR

\begin{tabular}{l||l||l||l||l} 
Refrigerant & $\begin{array}{l}\text { Molecular } \\
\text { Weight } \\
(\mathrm{kg} / \mathrm{kmole})\end{array}$ & $\begin{array}{l}\text { Liquid } \\
\text { density } \\
\left(\mathrm{kg} / \mathrm{m}^{3}\right)\end{array}$ & $\begin{array}{l}\text { Critical } \\
\text { Temp. } \\
{ }^{\circ} \mathrm{C}\end{array}$ & $\begin{array}{l}\text { Critical } \\
\text { Pressure } \\
\mathrm{MPa}\end{array}$ \\
\hline HFC-134a & 102 & 1225.3 & 101.1 & 4.06 \\
\hline HC-600a & 58.1 & 556.9 & 134.7 & 3.64
\end{tabular}

Since the latent heat of HC-600a $(364.25 \mathrm{~kJ} / \mathrm{kg})$ is much higher than that of HFC-134a $(216.87 \mathrm{~kJ} / \mathrm{kg})$, the amount of refrigerant charge can be reduced.

\section{RESULTS AND DISCUSSIONS}

The transient temperatures at the inlet and outlet of the evaporator, cabin and freezer compartment, compressor, condenser and the electric power consumption were measured and recorded continuously for a cycle through a data acquisition system as well. As stated before, cabin and freezer temperatures were measured (six thermocouples for cabin and three thermocouples for freezer). Based on these measured temperatures, arithmetic averages of instantaneous cabin and freezer temperatures were calculated for each test. The obtained data are plotted in figures for comparison and the results are analyzed and discussed in the following in details. The power consumption, working time, and on-time ratio of the compressors were calculated.

\section{A- Pull-down time test}

As mentioned in section (II) that some modifications on the refrigerator tube connections is carried out to install another constant speed compressor to the system. The refrigerator originally designed to work with HFC-134a. Therefore, it's necessary to estimate the new optimum refrigerant charge for HC-600a as well as for HFC-134a refrigerant. At optimum refrigerant charge, lowest pull-down time, discharge pressure, energy consumption and the highest COP can be achieved for a specific refrigerator [16]. To conduct no load pull down test, the refrigerator doors were kept open until temperatures inside the refrigerated cabinet has reached the steady state condition with ambient. According to ISO 8187 , the pull-down time is the time required to reduce the air temperature inside the cabin and freezer compartments from ambient condition to the desired air temperatures [17]. The objective here is to reach the operating freezer and cabin air temperature from ambient temperature to $-19^{\circ} \mathrm{C}$ and $7{ }^{\circ} \mathrm{C}$, respectively.
Figure 3 ( $a$ and $b$ ) shows the average cabin and freezer compartment air temperatures at different refrigerant charges of HFC-134a and HC-600a versus operating time. The the pull-down tests are carried out to achieve the desired temperature in the specific time. The tests were repeated for $40 \mathrm{~g}, 55 \mathrm{~g}$, and $70 \mathrm{~g}$ of HC-600a and for $90 \mathrm{~g}, 110 \mathrm{~g}$, and 130 g charges of HFC-134a. Experiments were carried out the same way with HC-600a and HFC-134a refrigerants by following the same procedures. Continuous running tests were carried out with closed doors and No-load in refrigerator. Therefore, the refrigerator can be considered as a constant volume system. As operating time increases, heat absorbed from the internal air volume in the refrigerated cabinet increases causing the air temperatures to decrease as shown in Figure 4 for HFC-134a and HC-600a. Clearly, instantaneous and steady state cabin and freezer temperatures decrease as initial charge increases.

shown in the Fig. 3 (a), the operating conditions of $7{ }^{\circ} \mathrm{C}$ cabin and $-19{ }^{\circ} \mathrm{C}$ freezer air compartments for HFC-134a charges were achieved for charges of $130 \mathrm{~g}$ and $110 \mathrm{~g}$ at about 72 and $115 \mathrm{~min}$, respectively. It was observed also that the 90 $\mathrm{g}$ yield higher steady state air temperatures in both freezer and cabin. In addition, Fig. 3 (b) for HC-600a shows that the operating temperatures were also obtained for $55 \mathrm{~g}$ and $70 \mathrm{~g}$ charges at pull down time of 87 and 68 min, respectively. The Pull-down time of the $110 \mathrm{~g}$ charge for HC-600a is lower than the $55 \mathrm{~g}$ charge for HFC-134a by about $24.3 \%$.

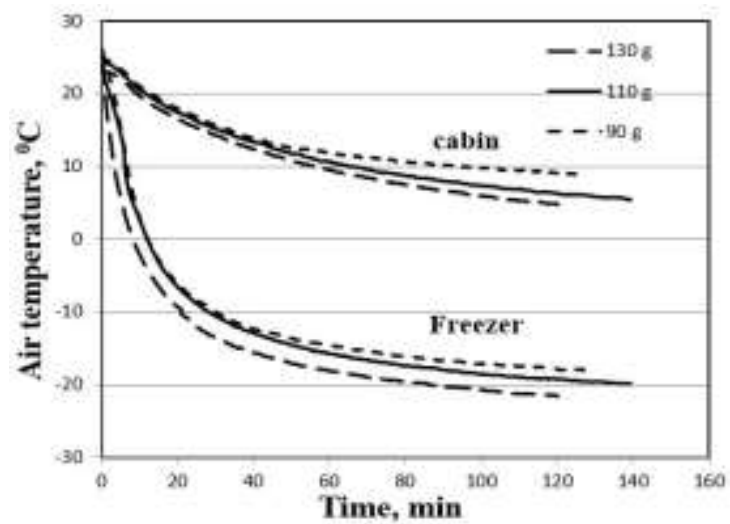

(a)

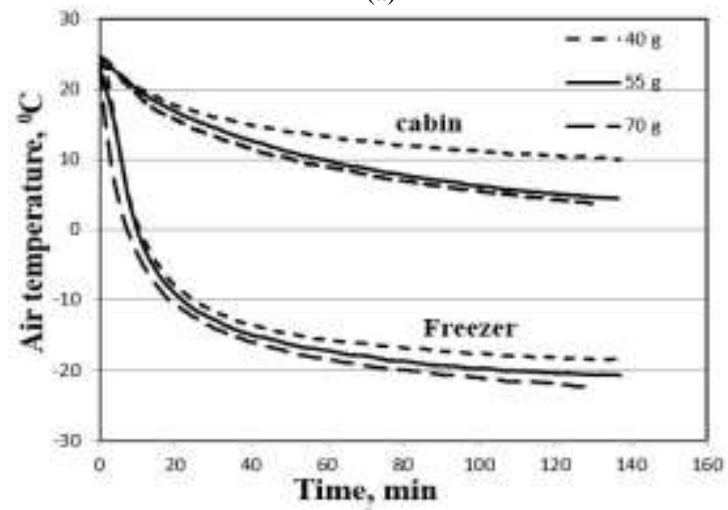

(b)

Fig. 3 Cabin and freezer compartment air temperature versus time for (a) HFC-134A and (b) HC-600A

As Mehdi [18] concluded that the power consumption by the system is too high when the compressor is charged with a 
large mass of refrigerant. In addition, lower refrigerant charge must be selected for environment and economic considerations. Therefore, the optimum refrigerant charge was selected of $110 \mathrm{~g}$ for HFC-134a and $55 \mathrm{~g}$ for HC-600a refrigerator. As shown, isobutene (HC-600a) has a smaller density than that of HFC-134a as listed in Table 1 and hence the amount of charge decreases significantly with HC-600a [3]. The optimum charge of HC600a was lower than HFC$134 \mathrm{a}$ by $50 \%$. Therefore, the annual energy consumption is expected to decrease by replacing HFC-134a with HC-600a in a refrigerator using HFC [16].

\section{B. Temperature and pressure measurements}

For the constant speed compressor, the refrigerator is driven by a conventional on-off control algorithm. Once the compressor starts up, it continues to operate until the average compartment air temperature reaches $7^{\circ} \mathrm{C}$ then it stops. The compressor restarts to run again when the temperature of the compartment rise. Figure 4 shows a typical temperature measurement from inlet and outlet of different component of the refrigerator with constant speed compressor for HC-600a and HFC-134a. The figure shows the inlet and outlet compressor temperatures ( $\mathrm{T}_{\text {comp,in }} \& \mathrm{~T}_{\text {comp, out }}$ ), the inlet and outlet evaporator temperatures $\left(\mathrm{T}_{\mathrm{e}, \text { in }} \& \mathrm{~T}_{\mathrm{e}, \mathrm{out}}\right)$, the outlet temperature of heat exchanger $\left(\mathrm{T}_{\mathrm{HE}, \mathrm{out}}\right)$, the outlet temperature of condenser $\left(\mathrm{T}_{\text {cond,out }}\right)$ and cabin air temperature $\left(\mathrm{T}_{\text {air, cabin }}\right)$.
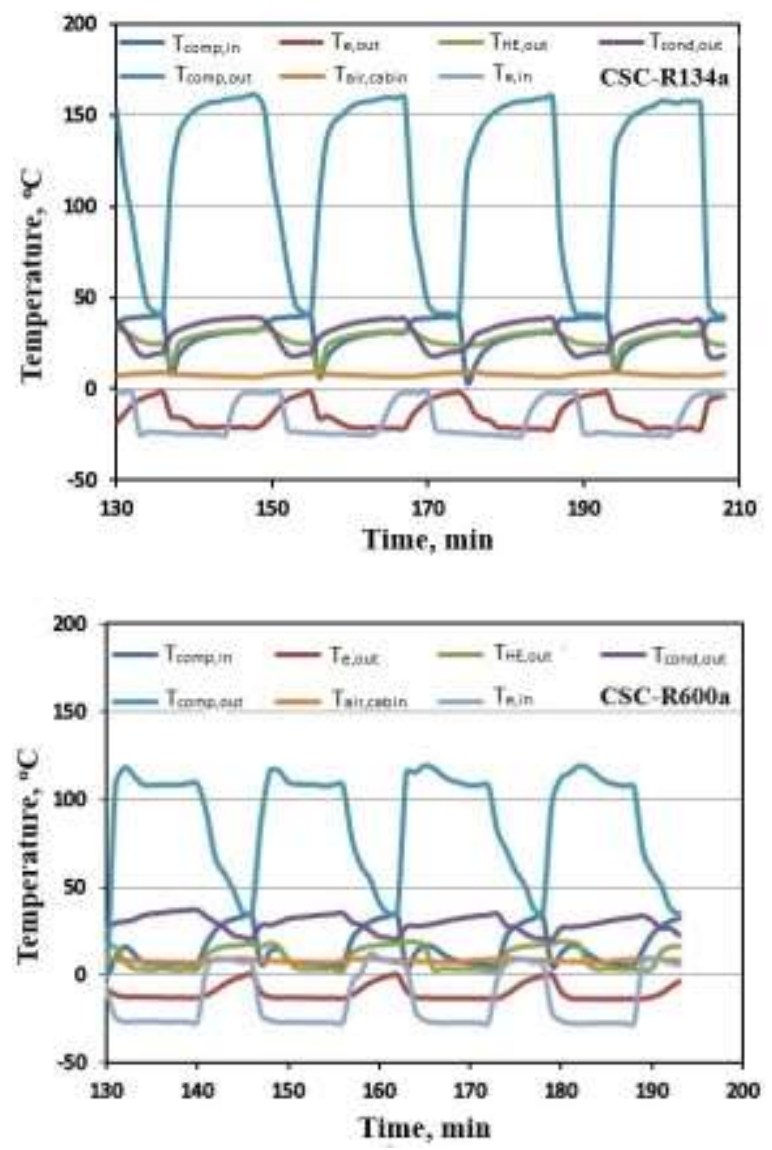

Fig. 4 Temperature measurements from inlet and outlet component of the constant speed compressor
Figure 5 shows a typical averaged temperature measurement from inlet and outlet of different component of the refrigerator with variable speed compressor for HC-600a and HFC-134a.

The suction and delivery pressures of the compressors during the steady state period are shown in Fig. 6 and Fig. 7. The constant speed compressor on-time are $63.2 \%$ and $62.5 \%$ of the time by using HFC-134a and HC-600a respectively. The measured low and high pressures for HFC-134a are 1.25 and 15.65 bar respectively but these values are measured as 1.28 and 14.4 bar for HC-600a. The presence of HC-600a in the refrigerating system leads to increase the evaporation pressure and reduce the condensing pressure in comparison with HFC-134a due to different charges and thermal properties. The introducing of $\mathrm{HC}-600 \mathrm{a}$ as replacement of HFC-134a with variable speed compressor leads to a reduction in evaporation pressure from 0.85 to 0.41 bar while the condensing pressure increased from 14.96 to 15.87 bar. The variable speed compressor on-time are $62 \%$ and $47.7 \%$ of the time by using HFC-134a and HC-600a respectively
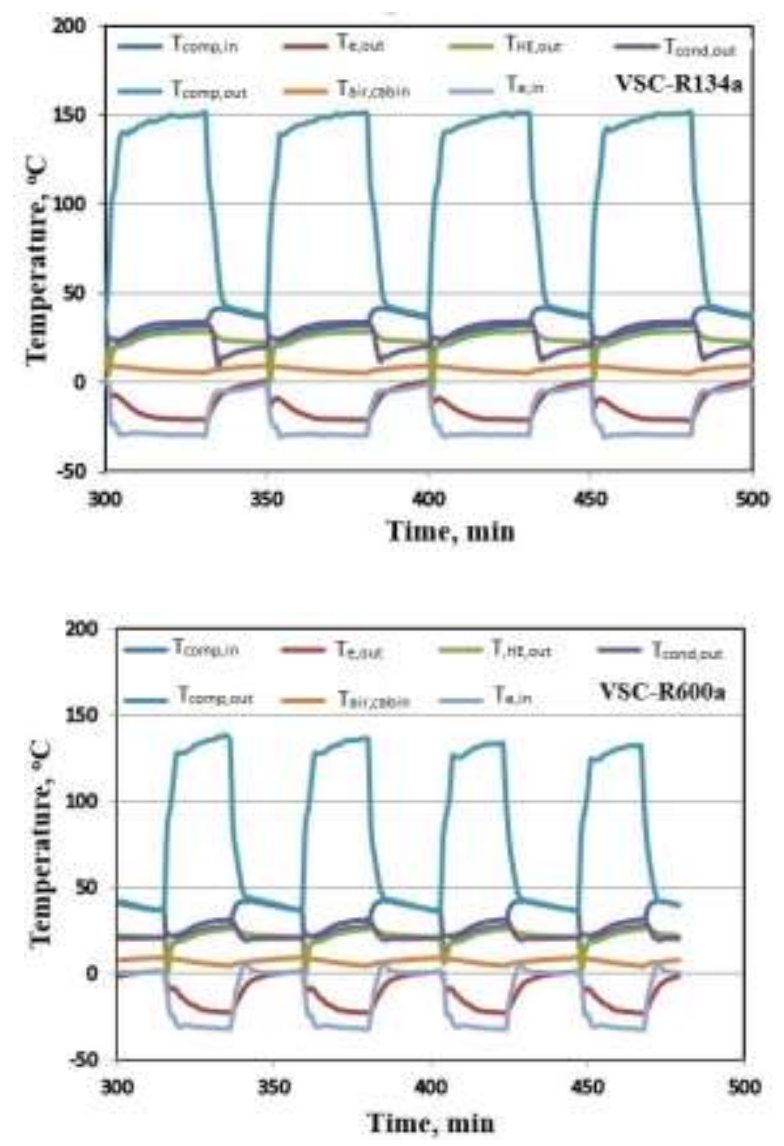

Fig. 5 Temperature measurements from inlet and outlet component of the variable speed compressor 


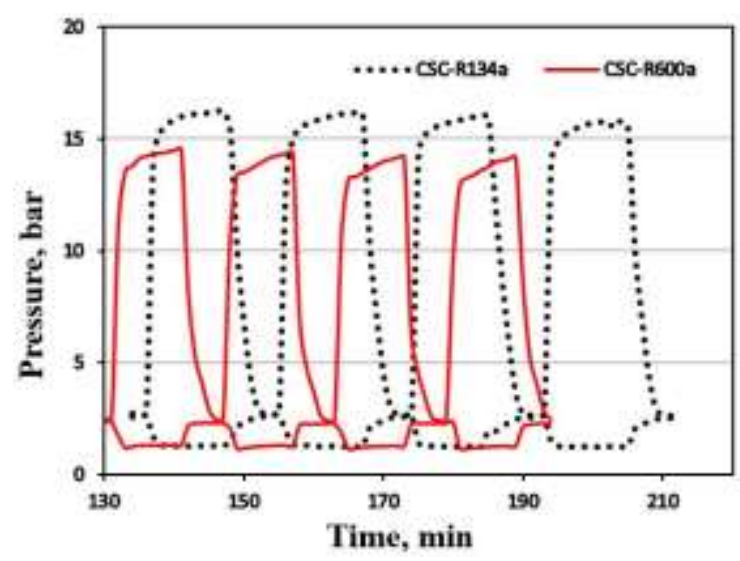

Fig. 6 Low and high-pressure measurements with constant speed compressor

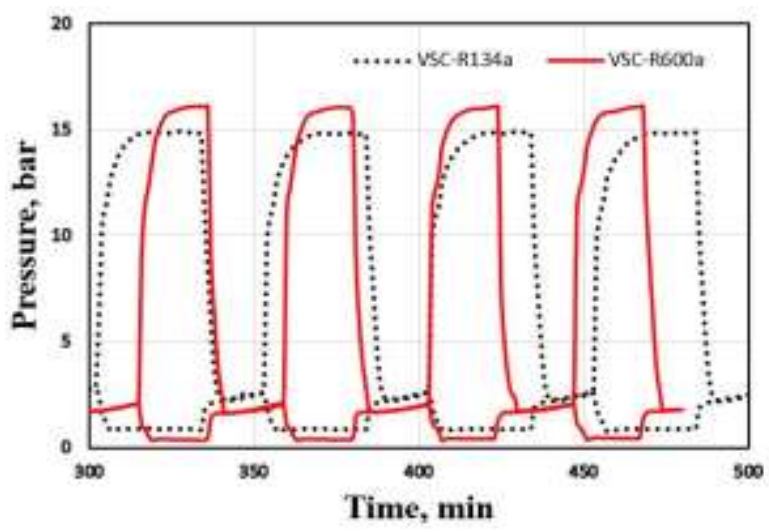

Fig. 7 Low and high-pressure measurements with variable speed compressor

\section{Performance characteristics}

To calculate the daily energy consumption of the refrigerator, the instantaneous power consumption data of the compressor should be given. In this section, the performance and power consumption of both constant and variable speed compressors with HC-600a and HFC-134a refrigerants carried out. In addition, a comparison in the performance and energy consumption will be presented.

\section{C-1 Performance characteristics with constant speed compressor}

Figure 8 shows the instant electrical power consuming recorded

for the constant speed compressor with the time when the system working with HFC-134a and HC-600a. In other words, it presents the power consumption for HFC-134A and HC600a refrigerants at its optimized charge using constant speed compressor. At the starting of the compressor, it can be observed that the compressor power is high and can reaches $320 \mathrm{~W}$ (HFC-134a) in a small time is due to the high start-up torque of the constant speed compressor. Furthermore, the power is fluctuating in the first 40 minutes around the $200 \mathrm{~W}$ in the unsteady state period for both refrigerants. This may be attributed to the short of lubricant oil between the piston surface and the cylinder wall as discussed by Lu et al. [19]. After 40 minutes of start-up, the power fluctuation is insignificant and can be considered as constant. It is clear that the on-time period of the first start-up process with HC-600a is shorter than that of HFC-134a. The steady state period is examined to calculate the energy consumption of the refrigerator per day. As it was predicted, at the zero time (when compressor starts) the power consumption for both the refrigerants was high but it soon decreased to an almost constant value. When the cabin compartment reaches around a preset temperature of $7{ }^{\circ} \mathrm{C}$, the compressor is turned OFF at around $125 \mathrm{~min}$ and the power consumption becomes zero. The average power consumption and compressor on-time ratio determines refrigerator energy consumption. As shown in Fig. 8, the HFC-134a had a higher power consumption than HC$600 \mathrm{a}$ in the starting period (0 to $40 \mathrm{~min}$ ).

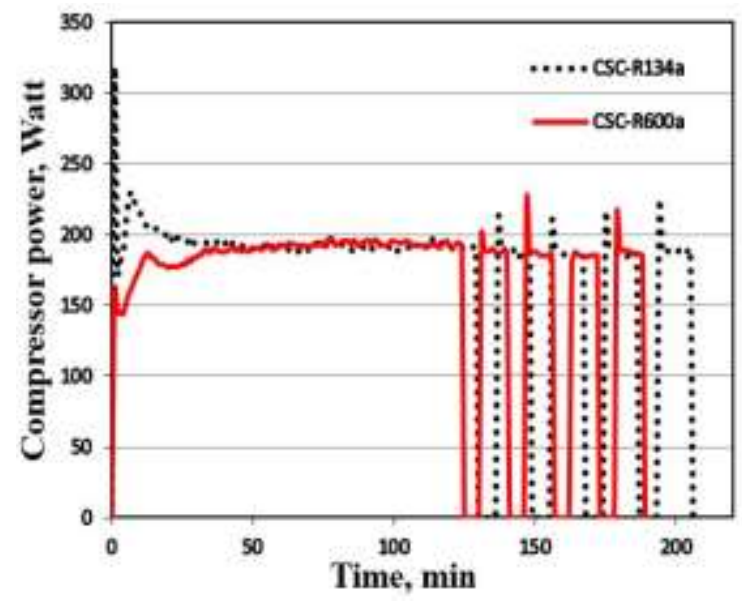

Fig. 8 Variation of instantaneous power consumption of the constant speed compressor with the time

In the steady state, both of refrigerants had the same trend. However, conventional HFC-134a compressor long on-time period makes energy consumption of HFC134a more than HC-600a. For HC-600a, the on-time and off-time would be 10 and 6 minutes, respectively with power of $188 \mathrm{~W}$ and energy consumption of $2.83 \mathrm{kWh} /$ day. The power consumed for HFC-134a is $189 \mathrm{~W}$ with 12 minutes on-time and 7 minutes off-time for the compressor and the energy consumption is $2.87 \mathrm{kWh} / \mathrm{day}$. This could be revealed by calculating the surface area under the curves. Besides, defrost runs after five six compressor working hours ( $\mathrm{ON}$ and $\mathrm{OFF}$ ), thus, due to more HFC-134a compressor on-time ratio, this refrigerant causes more defrost operations in a $24 \mathrm{~h}$ period than HC-600a.

The energy consumption, on-time ratio (compressor work percent), and on-time period in one cycle are the most important information which can be acquired from this figure. The calculated COPs during the steady state period of both HFC-134a and HC-600a refrigerants are compared in Fig. 9. 


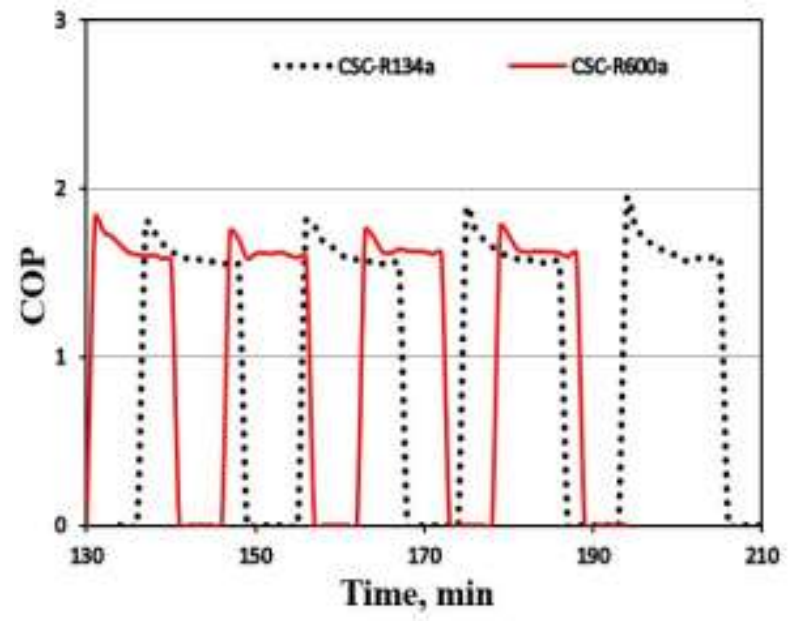

Fig. 9 Variation of system COP of constant speed compressor

As shown, the HFC-134a system presents a value of 1.789 compared with a value of 1.817 for HC-600a. Such slight increase in $\mathrm{COP}$ is attributed to the slight increase in evaporator temperature and hence the cooling capacity. The previous results showed that HC-600a with constant speed compressor saves energy by $1.2 \%$ comparison to HFC-134a. However, no significant changes in energy consumption and COP of the refrigerator, HC-600a seems to be a good alternative to HFC-134a from the environmental concern.

\section{C-2Performance characteristics with variable speed compressor}

Figure 10 shows the transient power consuming by using variable speed compressor versus the time with both HFC134a and HC-600a at its optimized charge. As shown and comparing with the power consumption curve of the constant speed compressor in Fig. 9, the fluctuations at the starting point is vanish. The variable speed technique eliminates the highly needed power in the starting which minimize the wear in the wall of the compressor and extend its lifetime.

In the first start-up process, the power is reduced smoothly due to reduction in compressor speed according to the algorism of the compressor. As mentioned before, the inverter reduces the compressor speed by frequency reduction as the cooling load is reduced. Also, the on-time period of the first process with HC-600a is shorter than that of HFC-134a. The steady state power consumed for HFC-134a is about $130.2 \mathrm{~W}$ with 31 minutes on-time and 19 minutes off-time for the compressor and the energy consumption is about 1.937 $\mathrm{kWh} /$ day.

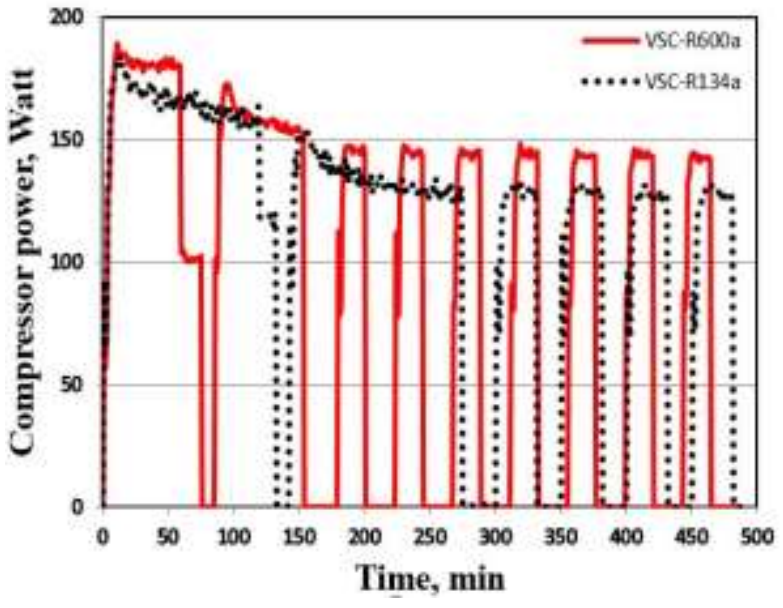

Fig. 10 Variation of the instantaneous power consumption of the variable speed compressor with the time

For HC-600a compressor, the on-time and off-time are 21 and 23 minutes with a power of $148.9 \mathrm{~W}$. The energy saving by using HC-600a is $12 \%$ in comparison to HFC-134a, which consumes $1.706 \mathrm{kWh} /$ day. This power saving is attributed to the lower on-time ratio of the compressor with HC-600a, which is $47.7 \%$, compared with HFC-134a of $62 \%$ on-time ratio. The steady state $\mathrm{COP}$ of the refrigerator working with HFC-134A and HC-600a are shown in Fig. 11. As shown, the use of HC-600a presents a value of 1.992 compared with a value of 1.931 for HFC-134a.

\section{D- Performance improvements using variable speed compressor}

From the previous results, it is clear that the energy consumption of a refrigerator can be minimized by using variable speed compressor technique regardless of the type of the refrigerant. In addition, using HC-600a as alternative to the conventional HFC-134a refrigerant offer good drop-in from the standpoint of COP, refrigerant charges, and energy consumption. Therefore, applying variable speed capacity control with using hydrocarbon refrigerant has much more energy saving. The experimental results are summarized in Table 2.

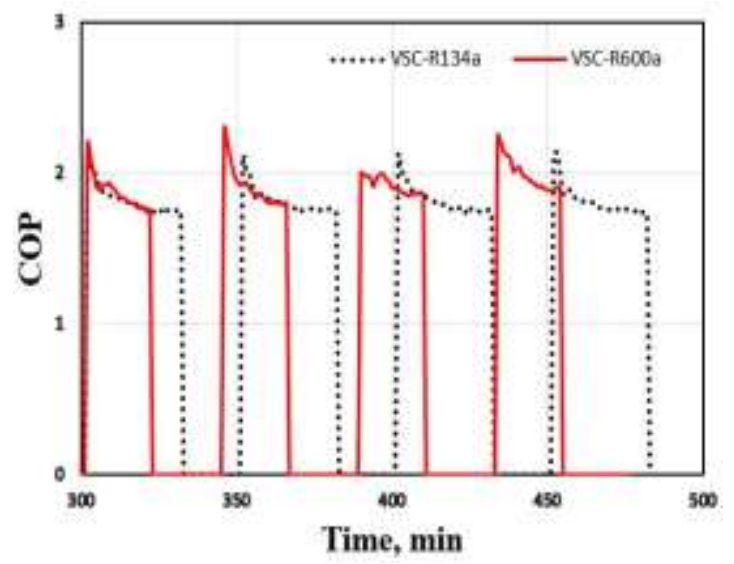

Fig. 11 Variation of system COP of variable speed compressor with time at different refrigerants 
TABLE 2

\begin{tabular}{|c|c|c|c|c|}
\hline \multicolumn{5}{|c|}{ ENERGY CONSUMPTION, COP AND ON-TIME RATIO } \\
\hline Quantity & $\begin{array}{c}\text { CSC-HFC- } \\
134 \mathrm{a}\end{array}$ & $\begin{array}{c}\text { CSC- } \\
\text { HC-600a }\end{array}$ & $\begin{array}{l}\text { VSC-HFC- } \\
134 \mathrm{a}\end{array}$ & $\begin{array}{l}\text { VSC- } \\
\text { HC- } \\
600 a\end{array}$ \\
\hline $\begin{array}{l}\text { Coefficient of } \\
\text { performance } \\
\text { (COP) }\end{array}$ & 1.789 & 1.817 & 1.931 & 1.992 \\
\hline $\begin{array}{l}\text { On time ratio, } \\
\%\end{array}$ & 63.2 & 62.5 & 62 & 47.7 \\
\hline $\begin{array}{l}\text { Energy } \\
\text { consumed per } \\
\text { day (DEC), } \\
\text { kWh/day }\end{array}$ & 2.856 & 2.831 & 1.937 & 1.706 \\
\hline
\end{tabular}

\section{CONCLUSIONS}

In this work a comparative investigation between constant and variable speed compressor are carried out with HC-600a and HFC-134a refrigerants in a domestic refrigerator. Pull down time tests are carried out and it found that the optimum charges were $110 \mathrm{~g}$ for HFC-134a and $55 \mathrm{~g}$ for HC-600a refrigerator. The use of variable speed compressor with hydrocarbons as refrigerants are not just good for energy saving but also for environment and offer good drop-in replacements for the existing constant speed compressor and traditional refrigerants. The introduction of variable speed compressor with inverter instead of constant speed compressor reduces the energy consumption and improves COP. Applying the variable speed technique, VSC-HC-600a and VSC-HFC$134 \mathrm{a}$ saves $40.5 \%$ and $32.4 \%$ of energy consumption, respectively in comparison to CSC-HFC-134a. COP of VSCHC-600a and VSC-HFC-134a are higher than CSC-HFC-134a by $10.8 \%$ and $7.4 \%$, respectively.

\section{REFERENCES}

[1] K. Harby, Doaa R. Gebaly, Nader S. Koura, Mohamed S. Hassan, (2016). Performance improvement of vapor compression cooling systems using evaporative condenser: An overview. Renewable and Sustainable Energy Reviews, 58,347-360.Available: https://www.sciencedirect.com/science/article/pii/S1364032115016962

[2] M. Rasti, S. Aghamiri and M. S. Hatamipour (2013). Energy efficiency enhancement of a domestic refrigerator using R436A and R600a as alternative refrigerants to R134a. International Journal of Thermal Sciences, 74 , 86-94. https://www.sciencedirect.com/science/article/pii/S129007291300166X

[3] K. Harby, (2017). Hydrocarbons and their mixtures as alternatives to environmental unfriendly halogenated refrigerants: An updated overview. Renewable and Sustainable Energy Reviews, 73, 1247-1264. https://www.sciencedirect.com/science/article/pii/S1364032117302551

[4] T. Q. Qureshi and S. A. Tassou (1996). Variable-speed capacity control in refrigeration systems. Applied Thermal Engineering, 16(2), 103-113. https://www.sciencedirect.com/science/article/pii/135943119500051E

[5] W. Chang, T. Shaut,C. Lin and K. Lin. Implementation of InverterDriven Household Refrigerator/Freezer Using Hydrocarbon Isobutane for
Refrigeration. International refrigeration and air conditioning conferencePurdue university Available: https://docs.lib.purdue.edu/iracc/945/, 2008

[6] K. Harby, Y. G. Nasr, E. H. Nour El-deen and A.M. El-Kersh "Hydrocarbons as Alternatives to the Environmental Harmful Refrigerants", Proceedings of 3rd International Conference on Energy Engineering Faculty of Energy engineering - Aswan University, Egypt, December 28-30, 2015.

[7] S. Dhavale, S. and D. M. Deshmukh (2016). Performance Comparison of Hydrocarbon Refrigerant as Isobutane R600a and Propane R290 in Domestic Refrigerator as Alternative Refrigerants to R134a. Invention Journal of Research Technology in Engineering \& Management (IJRTEM), 1, 2455-3689.

[8] C. C. Yu and T. P. Teng (2014). Retrofit assessment of refrigerator using hydrocarbon refrigerants. Applied thermal engineering, 66(1-2), 507-518.

Available: https://www.sciencedirect.com/science/article/pii/S1359431114001422

[9] C. S. Jwo, C. C. Ting, and W. R. Wang (2009). Efficiency analysis of home refrigerators by replacing hydrocarbon refrigerants. Measurement, 42(5), 697-701. Available: https://www.sciencedirect.com/science/article/pii/S0263224108001930

[10] M. Mohanraj, S. Jayaraj, C. Muraleedharan and P. Chandrasekar (2009). Experimental investigation of R290/R600a mixture as an alternative to $\mathrm{R} 134 \mathrm{a}$ in a domestic refrigerator. International Journal of Thermal Sciences, 48(5), 1036-1042.Available: https://www.sciencedirect.com/science/article/pii/S1290072908001683

[11]M. Y. Lee, D. Y. Lee and Y. Kim (2008). Performance characteristics of a small-capacity directly cooled refrigerator using R290/R600a (55/45). International journal of Refrigeration, 31(4), 734-741. Available: https://www.sciencedirect.com/science/article/pii/S0140700707002198

[12]M. A. Sattar, R. Saidur and H. H. Masjuki (2007). Performance investigation of domestic refrigerator using pure hydrocarbons and blends of hydrocarbons as refrigerants.

[13]M. Fatouh and M. El Kafafy (2006). Experimental evaluation of a domestic refrigerator working with LPG. Applied Thermal Engineering, 26(14),1593-1603.

Available: https://www.sciencedirect.com/science/article/pii/S1359431105004163

[14]C. Barthel and T. Gotz, (2012). Test procedures, measure-ments and standards for refrigerators and freezers. Wuppertal Institute for Climate, Environment and Energy, Germany. Available: https://energypediatest.energypedia.info/images/4/4c/Bigee_refrigerators_freezers_test_proc edures.pdf

[15]B.O. Bolaji, (2010). Experimental study of R152a and R32 to replace R134a in a domestic refrigerator. Energy, 35(9), 3793-3798. Available: https://www.sciencedirect.com/science/article/pii/S0360544210003014

[16] M. Mohanraj, S. Jayaraj, C. Muraleedharan, P. Chandrasekar, Mohanraj, (2009). Experimental investigation of R290/R600a mixture as an alternative to R134a in a domestic refrigerator. International Journal of Thermal Sciences, 48(5),1036-1042. Available: https://www.sciencedirect.com/science/article/pii/S1290072908001683

[17]ISO, International Standard Organization, International Standard-8187, Household refrigerating appliances (refrigerators/freezers) characteristics and test methods, 1991, International Organization for Standardization, Switzerland.

[18]Mehdi Rasti, SeyedFoad Aghamiri*, Mohammad-Sadegh Hatamipour, (2013). Energy efficiency enhancement of a domestic refrigerator using $\mathrm{R} 436 \mathrm{~A}$ and R600a as alternative refrigerants to R134a. International Journal of ThermalSciences, 74,86-94. Available: https://www.sciencedirect.com/science/article/pii/S129007291300166X

[19]Z. Lu, G. Ding and C. Zhang (2004). Dynamic simulation of natural convection bypass two-circuit cycle refrigerator-freezer and its application: Part II: System simulation and application. Applied thermal engineering, 24(10),1525-1533.Available: https://www.sciencedirect.com/science/article/pii/S1359431103004046 